\title{
Sustainability and Financial Accounting: a Critical Review on the ESG Dynamics
}

\author{
Patrizia Tettamanzi $^{1} \cdot$ Giorgio Venturini $^{2} \cdot$ Michael Murgolo $^{1}[$ (i)
}

Received: 5 October 2021 / Accepted: 6 January 2022 / Published online: 13 January 2022

() The Author(s), under exclusive licence to Springer-Verlag GmbH Germany, part of Springer Nature 2022

\begin{abstract}
This study gives a depiction of what are the general directions taken by international institutions so to tackle the current health emergency and the most pressing environmental issues, such as climate change and COVID-19 (Schaltegger, 2020; Adebayo et al., 2021).

The role of companies is crucial under disruptive events, such as a crisis or, more in line with the present time, a pandemic, and the pursue of the shareholder value cannot be the essence and the only objective in doing business anymore, since also ESG (i.e., environmental, social, and governance) dynamics have to be taken in due consideration. Moreover, an adequate and effective corporate governance should lead to higher disclosure quality, which subsequently should help protect the entire planet and ecosystems as well. In this context, the principal role of accounting and corporate reporting activities should be oriented towards making emerge what is and what is not done by companies in their business operations, and the disclosure of financial information is currently deemed inappropriate for pursuing a sustainable growth in the medium and long run (Schaltegger, J Account Org Change 16:613-619, 2020; Kirikkaleli \& Adebayo, Sustain Dev 29:583-594, 2020; Tettamanzi, Venturini \& Murgolo Wider corporate reporting: La possibile evoluzione della Relazione sulla Gestione Bilancio e Revisione, IPSOA - Wolters Kluwer, Philadelphia, 2021). Thus, the objective of this study is to investigate what international and European institutions have planned to do in order to align corporate objectives with environmental and societal needs in the coming years (Biondi et al., Meditari Account Res 28:889-914, 2020; Songini L et al. Integrated reporting quality and BoD characteristics: an empirical analysis. J Manag Govern, 2021).

As of today, our analysis finds that IFRS Foundation (at global level) and EFRAG (at European one) have been taking steps toward the aforementioned issues so to propose disclosure standards more in line with sustainability and environmental needed improvements. In fact, we tried to give a depiction of what are the actual and future strategies that both these institutions are going to put in place: this snapshot will give scientists, engineers, lawyers, and business people an overview of what should be like the corporate world of the near future, from a corporate reporting/accounting perspective (so to better understand what will be expected from companies of all the industries worldwide).
\end{abstract}

Keywords ESG Dynamics · Sustainability Reporting $\cdot$ Environment and Climate $\cdot$ Health Emergency

\section{Introduction}

Responsible Editor: Nicholas Apergis

Michael Murgolo

mmurgolo@liuc.it

1 School of Economics and Management, LIUC - Cattaneo University, Varese, Italy

2 Department of Accounting, Bocconi University, Milan, Italy
As it is apparent in the international arena, a relevant review of the general rules and the standards of corporate reporting is taking place. The major drivers of it are the climate issues urgency and a "deeper and more focused" stakeholders' engagement (Shan et al. 2021; Adebayo et al. 2021a, b).

Both public and private entities and institutions worldwide have been trying so far to tackle these issues in the most effective way, but only with COVID-19 spreading across the globe, we could maintain that these actions have begun to be more tangible and explicit. Consider the COP26 
meeting as an example (UK Government 2021). In November 2021, UK and Italy hosted an event considered the world last chance to get runaway climate change under control. Indeed, for nearly three decades, the UN has been bringing together almost every country on earth for global climate summits - called COPs, which stands for "Conference of the Parties" - and climate change, in that time, has "only" gone from being a fringe issue to a global priority. The COP held in November 2021 was the 26th annual summit and intended to reach an agreement with every nation on how to tackle climate change: 197 countries have agreed upon it, signing the "Glasgow Climate Pact". The set of decisions consists of a range of agreed items, such as strengthened efforts to build resilience to climate change, to curb greenhouse gas emissions, and to provide the necessary finance for both (UN Climate Change 2021a, b).

The UN 2030 Agenda as well as the most important international organizations have, therefore, managed to find an explicit solution to the issue in order to define a limit to, among others, those economic activities that — albeit profitable from a mere financial point of view - have, indeed, as a consequence, a negative impact for the environment and for the referential communities. In this, academic and scientific communities confirmed that accounting, reporting, and disclosure practices play a pivotal role in aligning the goals of the several stakeholders' strategies adopted at corporate level (Schaltegger 2020; La Torre et al. 2020; Kose \& Agdeniz 2021; Songini et al. 2021; Tettamanzi et al. 2021). In this regard, one of the COP26 outcomes was indeed related to "Transparency and Reporting", making emerge a set of rules through which countries shall be held accountable for delivering results related to their climate action plans and self-set targets under their nationally determined contributions (Kirikkaleli \& Adebayo, 2020; UN Climate Change 2021a, b; Adebayo et al. 2021a, b).

In Europe, this challenge has been faced by the European Commission which proposed in April 21, 2021 the draft for a directive regarding sustainability (i.e., CSRD "Corporate Sustainability Reporting Directive") that would essentially amend the requirements already defined in the area of "non-financial disclosure" within the framework of another directive, the NFRD "Non-Financial Reporting Directive". At the end of this drafting and enforcement legal procedure, we will be provided with a first set of sustainability accounting standards and principles to be potentially adopted starting from next October 2022. EFRAG "European Financial Reporting Advisory Group" (which is an association established in 2001 with the encouragement of the European Commission to serve the public interest with regards to international financial reporting standard initiatives at European level) has been appointed to define the aforementioned standards. Also the IFRS Foundation has been taking steps towards this issue, by means of the
IASB "International Accounting Standards Board" (founded in 2001 and responsible for the development, promotion and adoption of international financial reporting standard rules IFRS Foundation 2021). In this discussion article, we shall provide a snapshot of some of the most relevant global activities regarding sustainability at corporate level (Biondi et al. 2020; Songini et al. 2021), since only if disclosure and reporting activities expected by companies in the coming years are finally effective and in line with all the aforementioned needed improvements and objectives, business choices and practices - from which environmental and social concerns might arise - shall come more easily under scrutiny and be appropriately monitored.

\section{Sustainability Accounting: Initiatives at Global Level}

In essence, through this study, we will make emerge where the IASB (IFRS Foundation) and the EFRAG are heading towards with regards to sustainability reporting.

In general, since 2005, Regulation 1606/02 requires Europe to apply, under certain conditions, the IAS/IFRS (i.e., the international accounting standards) drawn up by the IASB and endorsed by EFRAG (Biondi et al. 2020). Having said that, with regard to sustainability reporting at European level, EFRAG appears to have been also entrusted with the corporate sustainability standard setting. Yet, since the scope of the IASB activities is wider and potentially covers the entire globe (with companies, for instance, in Japan and China, among the others, applying IAS/IFRS), it is also worth analyzing the IASB initiatives on this topic so to propose a broader perspective. That said, IASB/IFRS Foundation focus is mostly on listed companies, whereas the aforementioned CSRD proposal should address also privately-held ones; this makes emerge the reasons that stand behind the difference in their current set objectives also in terms of different final adopter (Biondi et al. 2020; La Torre et al. 2020; Songini et al. 2021).

Both at international level, with regard to the activities of the IASB and the IFRS Foundation, and at European level, through EFRAG, the direction of corporate reporting seems to be going in an increasingly value-oriented direction that goes beyond the financial results and beyond the creation of value for shareholders alone (UK HM Treasury 2021).

IFRS Foundation has announced the establishment under its control of a new board, the ISSB "International Sustainability Standards Board," which will be responsible for defining sustainability accounting standards to be applied in the coming financial years. This new board, whose members should possess specific expertise on ESG dynamics, will focus its drafting activity on material 
information for investors' decisions and other stakeholders in the world capital markets and on the urgent need for better information about climate-related matters (Schaltegger 2020; Adebayo et al. 2021a, b). In fact, the ISSB would initially focus on climate-related reporting, extending then its work towards the information needs of investors on other environmental, social, and governance (ESG) matters. EFRAG proposed to make its structure "dichotomous" as well, adding to the FRB "Financial Reporting Body", the NFRB "Non-Financial Reporting Body" - both appointed to carry out the required technical work according to their respective assigned tasks. In this context, it is worth stressing the importance of the interconnections between IASB and EFRAG, since in case of a complete independent development of ESG reporting standards by these two important institutions, the related standards might turn out to be incoherent and hardly comparable - which is necessarily something to avoid (La Torre et al. 2020; Kirikkaleli et al. 2021; Songini et al. 2021).

More in detail, the IFRS Foundation/IASB, as of today, has highlighted the strategic macro-decisions that should guide the future action of the ISSB, defining guidelines at a global level and basing the new standards first of all on the climatic issue, to be extended to the whole sustainability/ ESG sector in a broader sense. Furthermore, the creation of this new board has been announced at the UN Climate Change Conference (also known as COP26), held in November 2021. In essence, IFRS Foundation, by means of this and entrusting this board to set IFRS sustainability standards, will undergo a process of robust amendment of its governance, arranging its structure so to be better able to tackle the current and future ESG and sustainability challenges that the entire world has and will increasingly have to face (El Barnoussi 2020; García-Sánchez et al. 2020; Adebayo et al. 2021a, b; Shan et al. 2021).

EFRAG, on the other hand, with the objective of addressing the action plan for financing sustainable growth and facilitating dialog among stakeholders (European Reporting Lab - EFRAG 2021), has already been:

a) promoting the attitude that should be adopted by corporations towards the interest and public welfare (i.e., "public good"), through the disclosure of quality information, that should be both "retrospective" and "forward-looking";

b) calibrating the levels and boundaries of reporting on the uniqueness of each entity; and

c) recalling the concepts of double materiality and connectivity of information.

Please note that these mentioned points are key principles for drafting the most advanced global reports, such as integrated reporting. Moreover, EFRAG is pushing for producing an increasingly digitized and digitizable information that would definitely allow to overcome many anachronistic procedures still perpetrated in the accounting profession worldwide.

\section{Conclusions}

Underlining once again the apparent diversity, as of today, of set goals by the two institutions in discussion (i.e., EFRAG and IASB/ISSB), what does emerge at the moment is the willingness of both institutions to finally manage ESG dynamics also from an accounting and reporting perspective (UK HM Treasury 2021). In so doing, companies are increasingly required to provide high quality information that is also clear and comparable - potentially contrasting, subsequently, the "greenwashing" phenomenon. In this context, EFRAG concretely proposed a time plan of actions they have outlined and publicly declared (European Reporting Lab EFRAG 2021) that covers the next 6 years of activity. By 2022, they shall provide the final draft of two "conceptual frameworks" and the "core" topical standards, to be applied to FY23 for reports to be published in 2024 . EFRAG has also planned to treat the so-called advanced issues (if any) to be applied to FY25 and subsequent years, by 2024 .

To conclude, all these sustainability ventures will, sooner or later, also reach small and medium-sized companies (i.e., "SMEs") - mainly as the natural consequence of supply chain dynamics. Thus, the scope of application of the new sustainability reporting system shall potentially have a pervasive impact on the entire economic and social fabric of post COVID-19 Europe and the new millennium as well. Having said that, since this phenomenon is still evolving around the globe, from a legislative point of view, the matter in discussion is still in process and under scrutiny. Therefore, the snapshot should be taken as an overview of what will be potentially asked to companies in the coming future, being aware of the fact that radical changes to the above could be brought as well.

In fact, whether and what the actual impacts will be can only be defined in retrospect. Yet, it is worth underlining the actual (apparent) beginning towards a slightly broader and long-term vision of international institutions, making the principles of sustainability their own, without seeing them as the umpteenth "red tape" at global scale - moving, therefore, definitively on from a short termism attitude. That said, only by aligning integrated thinking with action will it be possible to definitively put in place sustainable and successful economic activities for all the communities involved. Otherwise, the price to be 
paid will be, once again, and increasingly unexpectedly, finding ourselves reliving devastating moments, similar to those that are still scourging the entire planet today, due to the ongoing pandemic crisis.

Author contribution This proposal of short discussion article was written only by the three aforementioned authors, i.e., Patrizia Tettamanzi (PT), Giorgio Venturini (GV), and Michael Murgolo (MM). More in detail, MM analyzed and interpreted the original documents drafted by IFRS Foundation and EFRAG. GV informed MM about the issue in analysis, giving him the documentary support needed for the first draft of the document. Besides, GV reviewed the initial work, proposing venues for necessary changes. PT as associate professor of Business Administration and $\mathrm{PhD}$ reviewed the final draft of the work, approving its submission. All authors read and approved the final manuscript.

Availability of data and materials All data are available in the main text and mentioned in the references.

\section{Declarations}

Ethics approval Not applicable.

Consent to participate Not applicable.

Consent to publish Not applicable.

Competing interests The authors declare no competing interests.

\section{References}

Adebayo TS, Oladipupo SD, Adeshola I, Rjoub H (2021) Wavelet analysis of impact of renewable energy consumption and technological innovation on $\mathrm{CO}_{2}$ emissions: evidence from Portugal. Environ Sci Pollut Res

Adebayo TS, Rjoub H, Akinsola GD, Oladipupo SD (2021) The asymmetric effects of renewable energy consumption and trade openness on carbon emissions in Sweden: new evidence from quantileon-quantile regression approach. Environ Sci Pollut Res

Biondi L, Dumay J, Monciardini D (2020) Using the international integrated reporting framework to comply with EU Directive 2014/95/ EU: can we afford another reporting façade? Meditari Account Res 28:889-914

El Barnoussi A, Howieson B, Van Beest F (2020) Prudential application of IFRS 9: (Un)fair reporting in COVID-19 crisis for banks worldwide? Aust Account Rev 30:178-192
European Reporting Lab - EFRAG (2021) Final report on proposals for a relevant and dynamic EU sustainability reporting standardsetting. EFRAG,

García-Sánchez I-M, Raimo N, Marrone A, Vitolla F (2020) How does integrated reporting change in light of COVID-19? A revisiting of the content of the integrated reports. Sustainability. 12:7605

IFRS Foundation (2021). Sustainability reporting - Agenda Paper of Lee White, IFRS Advisory Council

Kirikkaleli D, Adebayo TS (2020) Do renewable energy consumption and financial development matter for environmental sustainability? New global evidence. Sustain Dev 29:583-594

Kirikkaleli D, Güngör H, Adebayo TS (2021) Consumption-based carbon emissions, renewable energy consumption, financial development and economic growth in Chile. Bus Strat Environ 2021:1-15

Kose T, Agdeniz S (2021) Analysis of data about COVID-19 disease in integrated reporting. J Account Tax Stud

La Torre M, Sabelfeld S, Blomkvist M, Dumay J (2020) Rebuilding trust: sustainability and non-financial reporting and the European Union regulation. Medit Account Res 28:701-125

Schaltegger S (2020) Unsustainability as a key source of epi- and pandemics: conclusions for sustainability and ecosystems accounting. J Account Org Change 16:613-619

Shan S, Ahmad M, Tan Z, Adebayo TS, Li RYM, Kirikkaleli D (2021) The role of energy prices and non-linear fiscal decentralization in limiting carbon emissions: tracking environmental sustainability. Energy 234:121-243

Songini L, Pistoni A, Tettamanzi P, Fratini F, Minutiello V (2021) Integrated reporting quality and $\mathrm{BoD}$ characteristics: an empirical analysis. J Manag Govern

Tettamanzi P, Venturini G, Murgolo M (2021) Wider corporate reporting: La possibile evoluzione della Relazione sulla Gestione. Bilancio e Revisione. IPSOA - Wolters Kluwer

Tettamanzi P, Venturini G, Murgolo M (Forthcoming) Accounting for sustainability: la Convergente (?) Dialettica tra IASB e EFRAG. Bilancio e Revisione. IPSOA - Wolters Kluwer

UK Government (2021) COP26 explained. UN Climate Change Conference UK 2021

UK HM Treasury (2021) UK welcomes work to develop global sustainability reporting standards alongside 40 international partners. Gov.uk.

UN Climate Change (2021) The Glasgow climate pact - key outcomes from COP26. UNFCCC Sites and Platforms, Brazil

UN Climate Change (2021) COP26 outcomes: transparency and reporting. UNFCCC Sites and Platforms, Brazil

Publisher's note Springer Nature remains neutral with regard to jurisdictional claims in published maps and institutional affiliations. 